\title{
Producing a Semi-automatic Profile Measuring Program (SPMP) in Body Silhouette for Elderly Women
}

\author{
HeeKyung $\mathrm{Oh}^{1)}$, Naomi Maruta ${ }^{2)}$, Shinobu Nagashima ${ }^{3)}$, and Taeko Hirokawa ${ }^{4) \dagger}$ \\ ${ }^{1)}$ Division of Environmental Clothing Studies, Bunka Gakuen University; Tokyo, Japan \\ ${ }^{2)}$ Faculty of Home Economics, Kyoritsu Women's University; Tokyo, Japan \\ ${ }^{3)}$ Information Science, Rikkyo University; Tokyo, Japan \\ ${ }^{4) \dagger}$ Advanced Study of Clothing Construction, Bunka Gakuen University; Tokyo, Japan
}

\begin{abstract}
This study presents a new method called the SPMP (Semi-automatic profile measuring program) to efficiently measure body shape in elderly women. SPMP can automatically measure the angle of axis (19 items), surface (17 items), lengths (14 items), heights (16 items), widths (13 items), and depth (6 items). In total these 85 items are automatically measured very quickly, accurately, and easily after manually marking an initial 36 points. The utility of SPMP was evaluated using several tests. When SPMP measuring results were compared with manual methods (using a ruler and protractor) in thirteen elderly women using a paired t-test, there was no significant difference found between them. Furthermore, when measurements from SPMP were compared with actual measurement results in selected items from seven elderly women's measurements, smaller mean differences were found than those defined by ISO 20685, with the exception of the abdominal area which moves easily with breathing. Seven independent measurements of a single elderly woman were made by seven students using SPMP, and the values of coefficient of variation were less than $5 \%$ for all but 8 items. Finally, this study analyzed the correlation of all 85 item measurements, and found that the angle from the upper chest to the neck towards the front in the axis curved forward as much as the axis angle from the thigh to the waist $(\mathrm{r}=-0.876$, $* * \mathrm{p}<0.01$ ) bent backwards in elderly women. This detailed analysis helps to understand age-related changes in body posture, and will be useful in future studies.
\end{abstract}

Key words: Semi-automatic profile measuring program (SPMP), profile of body silhouette, elderly women.

\section{Introduction}

Clothes are made for the body. In order to make clothes for elderly women, it is important to understand their body shape. The challenge in making comfortable clothes for elderly women is that each of them have different types of body shapes, and their body structures continuously change depending on living environments and life styles.

The profile of the body silhouette can help us to estimate body shape, such as the volume of darts and fit between clothes and areas of the body, e.g. the shoulders, armholes, and waist. Studies on the profile of body silhouettes (Miyoshi \& Nagatomi, 1993; Nam, 1991; Okabe \& Kurokawa, 2005a; Okabe \& Kurokawa, 2005b; Sugita et al., 2001; Takao, 1970; Yanagisawa et al., 1968) have been carried out to understand variation in body shape. However, in most cases, researchers studied only young women and not elderly women.

Some studies of body shape in elderly women have attempted to

$\dagger$ Corresponding author; Taeko Hirokawa

Tel. +82-3-3299-2278, Fax. +82-3-3299-2278

E-mail: hirokawa@bunka.ac.jp analyze body size data (Shiraishi \& Doi, 1982; Watanabe et al., 1999); however, these studies were limited to only surface angle at the back area, and not the entire body silhouette.

Until now, there has been no specific method of measurement or calculation for the profile of body silhouettes of elderly women. Instead, only studies about the entire body silhouette for elderly women (Igarashi \& Makabe, 2001; Iwasaki et al., 1997) have been explored. These studies applied calculation methods used in measurements of young women, but these may not be appropriate because the bodies of elderly women have different body silhouettes compared to young women, such as greater curvature of the back. One other study for elderly women has divided the body in other way, that is, from the ankle to the neck and from the waist to the most protruding point at back upper body, etc (Hirokawa, 2008). However, many different shapes, so that the back of the body and the lower body may curve forward or backward and weight may gain or lose with age. Therefore it needs detail measuring.

In order to understand elderly women's bodies, we need a detailed way to measure them using the profile of the body silhouette. For example, 1) in analyzing elderly women's contoured upper back shape and lower body, it is helpful to study the divisions of the body axis standard in greater detail. 2) The waist 
measurement of elderly women is usually measured based on the waist of a young woman. Therefore, it appears too high (close to the bust) for elderly women as weight changes with age, especially weight gain around the abdomen (Oh, 2010).

In this study, the 'Semi-automatic profile measuring program (SPMP)' is developed to provide a device for more specific body measurement, particularly in elderly women. SPMP is programmed in Visual C\#. Since it is not fully automatic, in order to measure an elderly woman's body using SPMP, 36 points are first marked directly on the profile of the body silhouette photo by the user (Oh, 2010). SPMP then uses these points to automatically calculate each of 85 measurement items. Although it is semi automatic, this method allows measurements to be made more quickly, accurately, and easily for elderly women than previous measuring devices which were more time consuming and relied on manual methods (e.g., by ruler and protractor).

\section{Method}

\subsection{Picking marking points on the photo}

Firstly, this paper suggests body factor points for processing by the computer program. In order to be used by the SPMP program, body measurement points first need to be defined on the silhouette by the user. Measurement points are described on the profile of body silhouette drawing below (Fig. 1), focusing on those used for elderly women's measurements. This study suggests mainly,

1) $\mathrm{FCP}(9), \mathrm{BCP}(10), \mathrm{MCP}(38)$ in the chest area for measuring the upper body's axis angle.

2) $\mathrm{AAP}(7), \mathrm{PAP}(8)$ in arm area for measuring the axilla's height,

3) $\mathrm{FWP}(16), \mathrm{BWP}(17), \operatorname{MWP}(39) / \mathrm{FBWP}(18), \operatorname{BBWP}(19)$, MBWP(40) / F-B凹(21), В凹(20), M-B凹(41) in the waist area for measuring the middle body's axis angle and height at each point,

4) $\mathrm{FTP}(30), \mathrm{BTP}(31), \mathrm{MTP}(42)$ in thigh area for measuring the axis angle,

5) $\mathrm{FKP}(32), \mathrm{BKP}(33), \mathrm{MKP}(43)$ in knee area for measuring the axis and surface angle etc.

These points follow Japanese Industrial Standards(2009), Miyoshi (2008), as well as include original suggestions from this paper.

\subsection{Choosing measurement items for elderly women}

Until now, the profile of body silhouette measurements for elderly women had not been defined and the same measurements were used as in young women. However, this study suggests a total of 85 measurement items for elderly women including Body Axis angle (19 items), Body Surface angle (17), Length (14), Height (16), Width (13) and Depth (6), described in detail below.

First, the division of the body axis angles to incorporate both elderly women's contoured upper body shape and lower body is necessary. In this study, the upper body axis is divided into two parts at the chest and the lower body axis is divided at the crotch

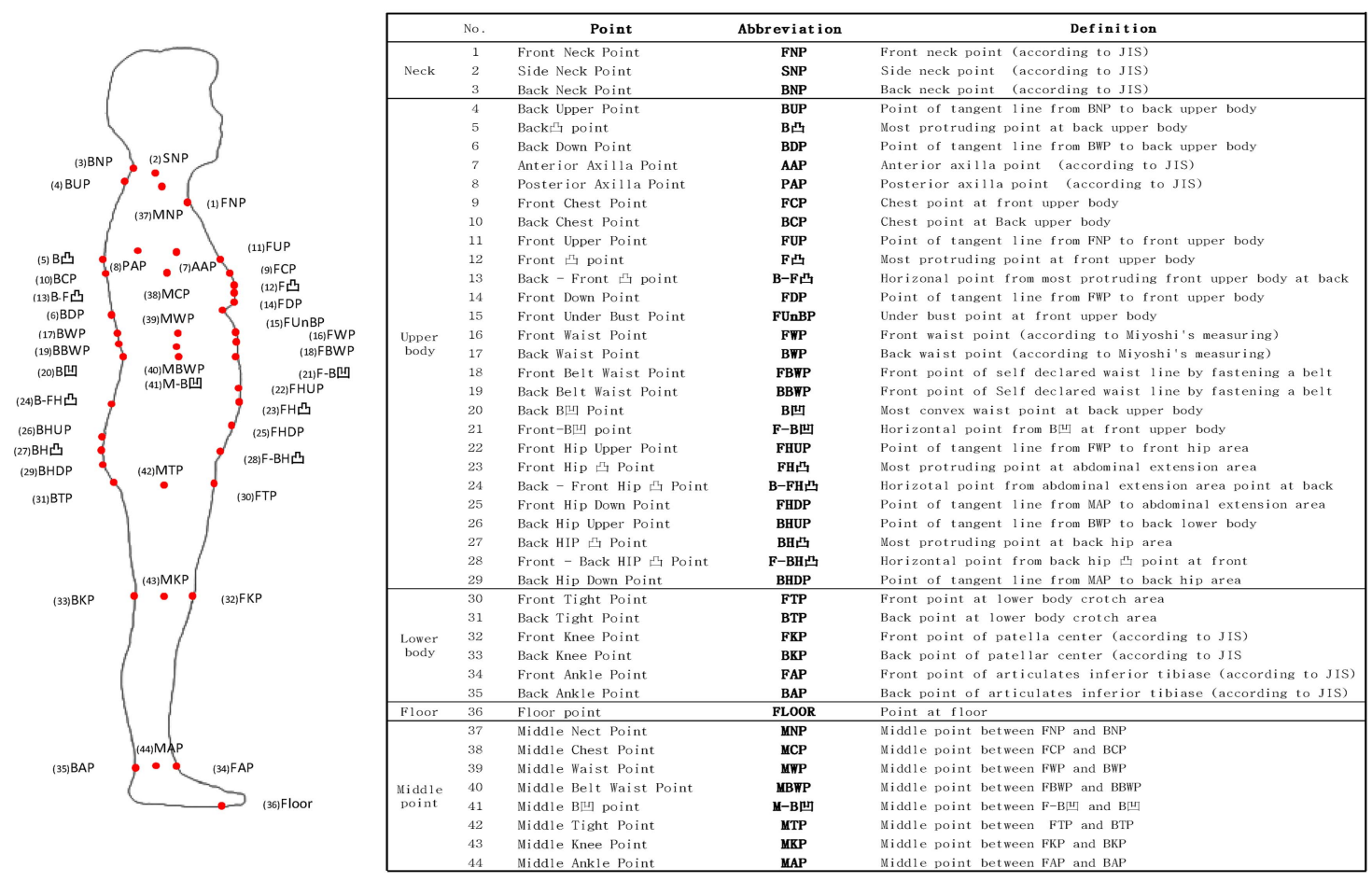

Fig. 1. Points in profile body silhouette with definition. 
and the knee. The body is further divided into 5 parts to more accurately measure bodies of elderly women, e.g., from the neck area to the chest, from the chest to the waist, from the waist to the crotch, from the crotch to the knee, and from the knee to the ankle.

Secondly, to understand the shape of elderly women who are usually obese around the waist, a new measurement for the waist lines of elderly women is needed. It can be measured at 3 separate positions at the waist as below.

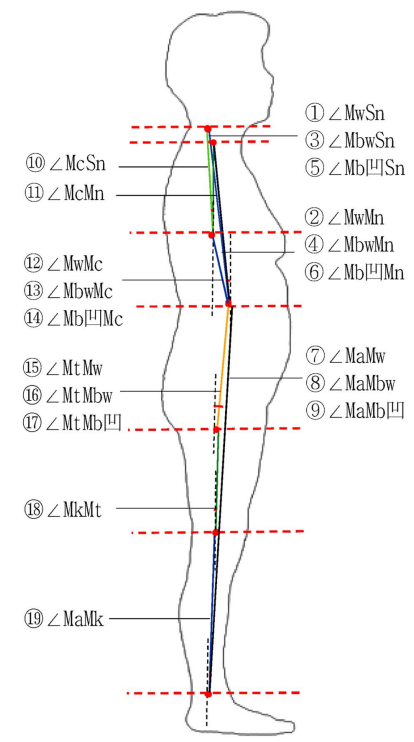

Fig. 2. Measurement item of axis angle in profile body.

Table 1. Measurement item of axis angle with start point and end point

\begin{tabular}{|c|c|c|}
\hline$\overline{\text { Body Axis item }}$ & Start Point & End Point \\
\hline$\angle(1) \mathrm{MwSn}$ & MWP & SNP \\
\hline$\angle$ (2) MwMn & MWP & MNP \\
\hline$\angle$ (3) MbwSn & MBWP & SNP \\
\hline$\angle$ (4) MbwMn & MBWP & MNP \\
\hline$\angle$ (5) $\mathrm{Mb} 凹 \mathrm{Sn}$ & М-В凹 & SNP \\
\hline$\angle$ (6) $\mathrm{Mb凹Mn}$ & М-В凹 & MNP \\
\hline$\angle(7) \mathrm{MaMw}$ & MAP & MWP \\
\hline$\angle 8 \mathrm{MaMbw}$ & MAP & MBWP \\
\hline$\angle 9 \mathrm{MaMb}$ & MAP & М-В凹 \\
\hline$\angle 10 \mathrm{McSn}$ & $\mathrm{MCP}$ & SNP \\
\hline$\angle(11) \mathrm{McMn}$ & MCP & MNP \\
\hline$\angle(12 \mathrm{MwMc}$ & MWP & MCP \\
\hline$\angle 13 \mathrm{MbwMc}$ & MBWP & MCP \\
\hline$\angle$ (14) $\mathrm{Mb} 凹 \mathrm{Mc}$ & М-В凹 & $\mathrm{MCP}$ \\
\hline$\angle(15) \mathrm{MtMw}$ & МTP & MWP \\
\hline$\angle$ (16) MtMbw & MTP & MBWP \\
\hline$\angle 17 \mathrm{MtMb凹}$ & MTP & М-В凹 \\
\hline$\angle 18 \mathrm{MkMt}$ & MKP & MTP \\
\hline$\angle 19 \mathrm{MaMk}$ & MAP & MKP \\
\hline
\end{tabular}

(1) The horizontal line at the deepest back portion of the waist, (Nakamoto \& Miyoshi, 1980) (2) the horizontal line at the right side of the slender waist (Miyoshi, 2008), and (3) the self declared waist line by fastening a belt (This belt waist position is not horizontal. This is the line from the front belt waist point to the back). This new study tries to measure using the method at the self declared waist line.

\subsection{Developing a Semi-automatic Profile Measuring Program (SPMP)}

In order to measure elderly women's measurement items (Fig. $2 \sim 5$, Tables 1 4) using the profile of the body silhouette, a Semi-

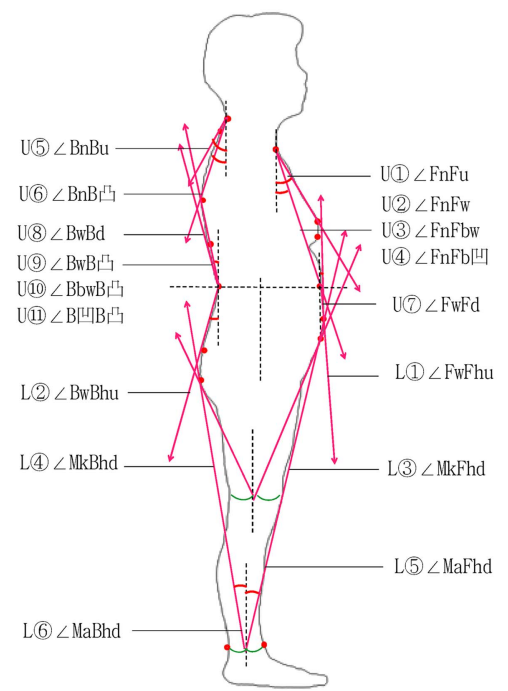

Fig. 3. Measurement item of surface angle in profile body.

Table 2. Measurement item of surface angle with start point and end point

\begin{tabular}{|c|c|c|}
\hline Body surface item & Start Point & End Point \\
\hline $\mathrm{U}(1) \angle \mathrm{FnFu}$ & FNP & FUP \\
\hline $\mathrm{U}(2) \angle \mathrm{FnFw}$ & FNP & FWP \\
\hline U(3) $\angle \mathrm{FnFbw}$ & FNP & FBWP \\
\hline $\mathrm{U}$ (4) $\angle \mathrm{FnFb}$ 凹 & FNP & F-В凹 \\
\hline $\mathrm{U}(5) \angle \mathrm{BnBu}$ & BNP & BUP \\
\hline $\mathrm{U}(6) \angle \mathrm{BnB}$ & $\mathrm{BNP}$ & В凸 \\
\hline $\mathrm{U}(7) \angle \mathrm{FwFd}$ & FWP & FDP \\
\hline $\mathrm{U}(8) \angle \mathrm{BwBd}$ & BWP & BDP \\
\hline $\mathrm{U}(9) \angle \mathrm{BwB}$ & BWP & В凸 \\
\hline $\mathrm{U}(10) \angle \mathrm{BbwB}$ & BBWP & В凸 \\
\hline U(11) $\angle \mathrm{B}$ 凹 凸 & В凹 & В凸 \\
\hline L(1) $\angle$ FwFhu & FWP & FHUP \\
\hline $\mathrm{L}(2) \angle \mathrm{BwBhu}$ & BWP & BHUP \\
\hline L(3) $\angle$ MkFhd & MKP & FHDP \\
\hline $\mathrm{L}(4) \angle \mathrm{MkBhd}$ & MKP & BHDP \\
\hline L(5) $\angle \mathrm{MaFhd}$ & MAP & FHDP \\
\hline L6) $\angle \mathrm{MaBhd}$ & MAP & BHDP \\
\hline
\end{tabular}




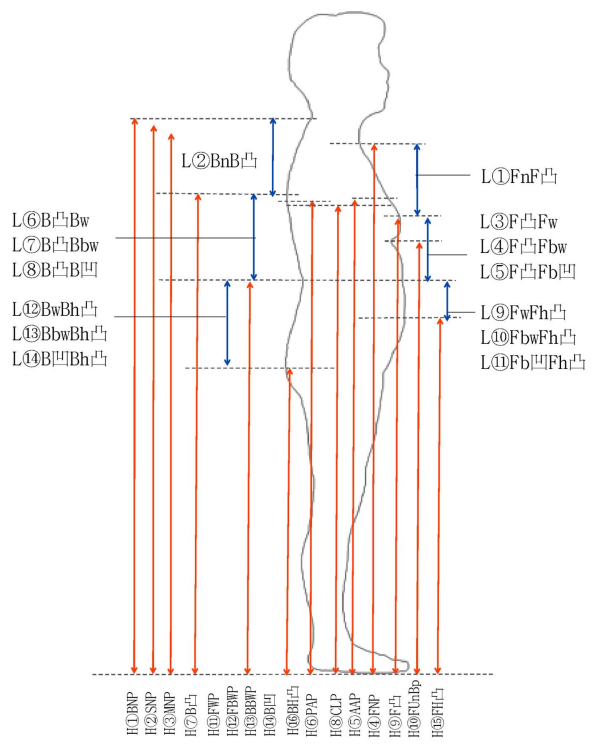

Fig. 4. Measurement item of vertical length and height in profile body.

Table 3. Measurement item of $\mathrm{V}$ ertical length and height with start point and end point

\begin{tabular}{|c|c|c|}
\hline Height item & Start Point & End Point \\
\hline L(1)FnF凸 & FNP & F凸 \\
\hline L(2) $\mathrm{BnB}$ & BNP & В凸 \\
\hline L(3) F凸Fw & F凸 & FWP \\
\hline L(4) $\mathrm{F}$ 凸 Fbw & F凸 & FBWP \\
\hline L(5)F凸Fb凹 & F凸 & F-B凹 \\
\hline L(6) $\mathrm{B}$ 凸 $\mathrm{Bw}$ & В凸 & BWP \\
\hline L(7)B凸Bbw & В凸 & BBWP \\
\hline L8)В凸В凹 & В凸 & В凹 \\
\hline L(9)FwFh凸 & FWP & FH凸 \\
\hline L(10FbwFh凸 & FBWP & FH凸 \\
\hline L(11)Fb凹Fh凸 & F-BШ & FH凸 \\
\hline L12BwBh凸 & BWP & ВН凸 \\
\hline L(13BbwBh凸 & BBWP & ВН凸 \\
\hline L(14)В凹Вh凸 & В凹 & ВН凸 \\
\hline H(1)BNP & BNP & FLOOR \\
\hline H(2) SNP & SNP & FLOOR \\
\hline H(3)MNP & MNP & FLOOR \\
\hline H(4)FNP & FNP & FLOOR \\
\hline H(5)AAP & AAP & FLOOR \\
\hline H(6) PAP & PAP & FLOOR \\
\hline Н(7)В凸 & В凸 & FLOOR \\
\hline H8CLP & CLP & FLOOR \\
\hline H(9)F凸 & F凸 & FLOOR \\
\hline H(10)FUnBP & FUnBP & FLOOR \\
\hline H(11)FWP & FWP & FLOOR \\
\hline H(12)FBWL & FBWL & FLOOR \\
\hline H(13)BBWL & BBWL & FLOOR \\
\hline Н(14)ВШ & В凹 & FLOOR \\
\hline H(15)ГН凸 & FН凸 & FLOOR \\
\hline Н(16) ВН凸 & ВН凸 & FLOOR \\
\hline
\end{tabular}

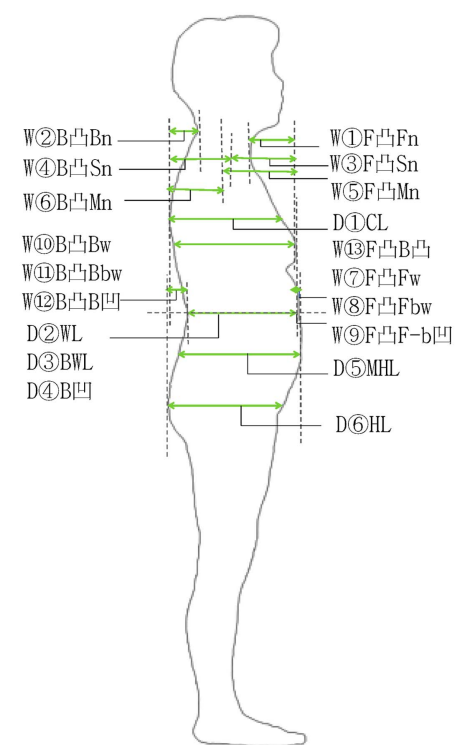

Fig. 5. Measurement item of horizontal width and depth in profile body.

Table 4. Measurement item of horizontal width and depth with start point and end point

\begin{tabular}{|c|c|c|}
\hline Width item & Start Point & End Point \\
\hline W(1)F凸Fn & F凸 & FNP \\
\hline W(2)В凸Bn & В凸 & BNP \\
\hline W(3)F凸Sn & F凸 & SNP \\
\hline $\mathrm{W}(4) \mathrm{B}$ 凸 $\mathrm{Sn}$ & В凸 & SNP \\
\hline W(5)F凸Mn & F凸 & MNP \\
\hline W(6)В凸Mn & В凸 & MNP \\
\hline W(7)F凸Fw & F凸 & FWP \\
\hline W(8)F凸Fbw & F凸 & FBWP \\
\hline W(9)F凸Fb凹 & F凸 & F-B凹 \\
\hline W(10)В凸Bw & В凸 & BWP \\
\hline W(11) $\mathrm{B}$ 凸bw & В凸 & BBWP \\
\hline W(12B凸В凹 & В凸 & В凹 \\
\hline W(13F凸В凸 & F凸 & В凸 \\
\hline D(1)CL & FCP & ВCP \\
\hline D(2)WL & FWP & BWP \\
\hline D(3)BWL & FBWP & BBWP \\
\hline D(4)B凹 & F-B凹 & В凹 \\
\hline D(5)MHL & FН凸 & В-FHґ \\
\hline D6)HL & F-BH凸 & ВН凸 \\
\hline
\end{tabular}

automatic Profile Measuring Program (SPMP) by Visual C\# 2010 Express was developed that is quicker and easier than previous methods. It is straightforward to construct an application on Visual $\mathrm{C \#}$ and insert photos into the program.

For using any size photo through SPMP, the object's length 
needs to be measured on the photo by comparing with an actual measurement before operating SPMP. Therefore, it needs to be compared and verified with the measurements of the real body silhouette. The ratio of reduction between the photo and actual measurement needs to be confirmed.

The difference in lengths between direct measurement and photography were verified with the below experiment, which was carried out with a ruler. Photos were taken of rulers including one vertical $(150 \mathrm{~cm})$ and four horizontal $(35 \mathrm{~cm}$ each) for comparison. Four horizontal $35 \mathrm{~cm}$ rulers were placed at the points at $0 \mathrm{~cm}$, $50 \mathrm{~cm}, 100 \mathrm{~cm}, 150 \mathrm{~cm}$, on a $150 \mathrm{~cm}$ long vertical ruler (Fig. 6). Then, the measurements from the picture of the setup of the rulers were taken to compare with the actual length of rulers. The ratio between the actual length of the ruler and the photographed ruler was measured for each set of rulers.

\subsection{Verification of SPMP}

2.4.1. Comparison of the values between SPMP and Manual Methods.

13 elderly women [mean (SD) age 72.67 (6.42) years, body mass $53.75(9.70) \mathrm{kg}$, height $150.65(5.13) \mathrm{cm}$ ] voluntarily participated in the study from September 2009 to December 2011. They were physically active and could come to Bunka Gakuen University, Shinjuku, Tokyo from their homes by themselves. For the study, participants were provided with undergarments (pants and bra) for the experiment. First, black triangular stickers were marked on the volunteers' bodies for use in clothes factors such as FNP, BNP, SNP, etc. Next, belts were handed out to each participant, asking them to fasten the belt at their waist.

Silhouette photos of each participant were taken using the 'Silhouetter System - 100'(Sakai Tokusyu Camera). This camera has two lenses: one on the top and one at the bottom of the box, taking pictures simultaneously which are then combined into a single image using computer software. This method helps to reduce errors and can be photographed close to the actual body silhouette measure (Nagatomi \& Saito, 2003). The corresponding measurements of the 85 items on 13 elderly women's profile of body silhouettes using both SPMP and a manual method (by ruler and protractor) were analyzed and a paired t-test was used to verify the differences between these two methods.

2.4.2. Comparison of the values between SPMP and Actual size 7 elderly women [mean (SD) age 77.00 (4.24) years, body mass $51.84(6.65) \mathrm{kg}$, height $148.07(2.73) \mathrm{cm}$ ] voluntarily participated for the study in December 2011. Body measurements were taken in some items using Martin's measurement; other body measurement methods follow those described in 2.4.1.

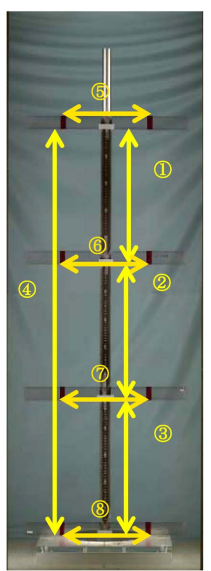

Fig. 6. Photo with rulers.

2.4.3. Comparison of values obtained from SPMP by different users Elderly woman's profile of body silhouettes were measured by seven students who are studying in the Division of Environmental Clothing Studies, Bunka Gakuen University Graduate School, in December 2011 using the SPMP program.

In order to help students accurately mark points, vertical and horizontal guide lines were drawn on the photo at the most protruding point and the main parts of the body (e.g. along the FNP, the FWP, etc), indicated by black triangular stickers on the body.

The students' measuring results were analyzed by calculating arithmetical average, standard deviation and coefficient of variation.

\section{Results and Discussion}

\subsection{Producing SPMP}

\subsubsection{Main function for SPMP}

First, the photo file for measuring is chosen, then each of 36 points are selected and marked on the photo. There are a total of 44 points in the silhouette, but middle points are automatically marked between front and back points. Therefore, only 36 marking points are required on each photo, and the combo-box has only 36 points (No.1 36 in Fig. 1) except 8 points (No.37 44 in Fig .1) for the middle one.

Due to the prior setting of the horizontal place corresponding to the front point (except FNP, FBWP; MNP lies in the middle of FNP and BNP, MBWP lies in the middle of FBWP and BBWP automatically but it is not horizontal), by clicking most of the front points of the profile body silhouette, each of the corresponding back points will be automatically adjusted to lie on the same height (except B 凹 ; F-B 凹 is automatically adjusted to lie on the same height after making B 凹 ). Thus, the midpoint between front and 


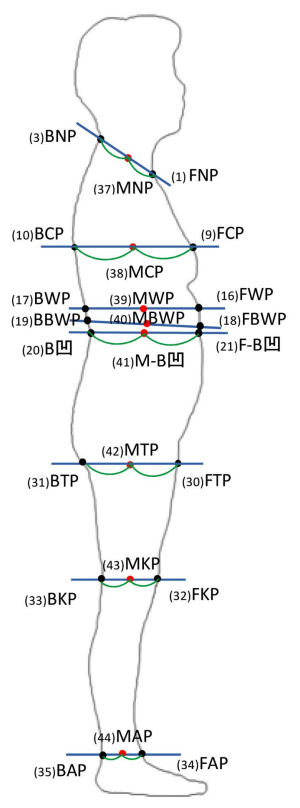

Fig. 7. Automatic middle point between front and back points.

back points can be accurately and easily obtained for the axis angle (Fig. 7).

Fig. 8 shows the main button operation in SPMP. All points can be removed, recalled, and the names of each point can be viewed with a click of a button. All 85 measurement results in angle and length are reflected after marking all 36 points, and are copied onto an Excel spreadsheet. The output file can be saved and reloaded for future viewing. Also, after determining the ratio between the actual measurement and its photo, the ratio is recorded in the black column next to the measurement button.

\subsubsection{Output of using SPMP}

Until now, profile of body silhouettes have been measured manually by photographs using the manual method (with a ruler and protractor), thus requiring a large investment of time and effort. But

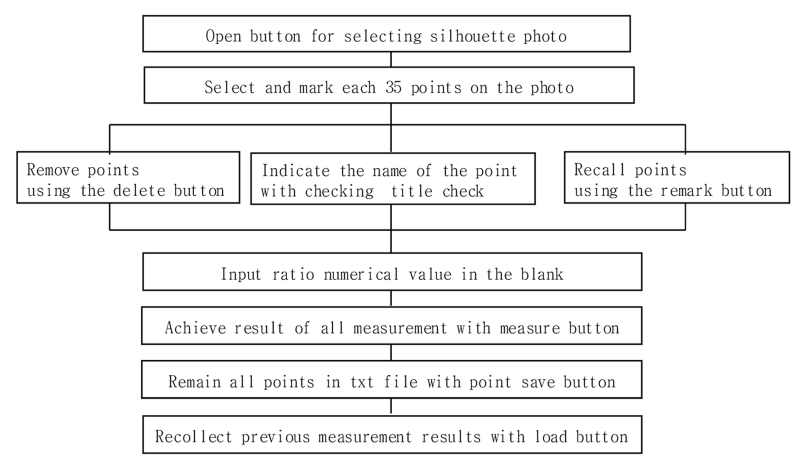

Fig. 8. Flow chart of button operation on SPMP.

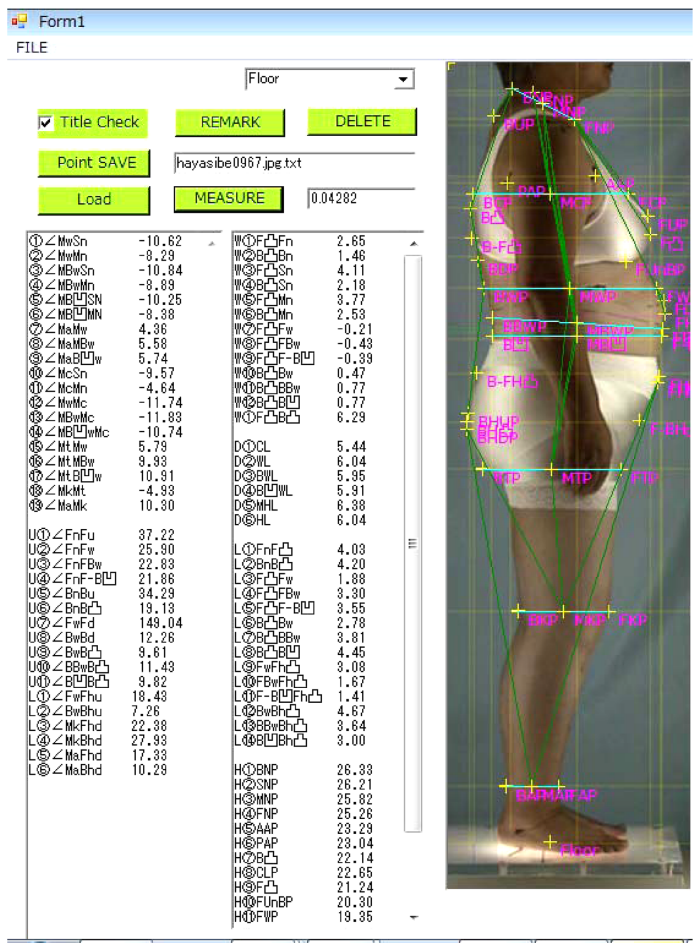

Fig. 9. Measurement of all items by the Semi-automatic Profile Measuring Program (SPMP).

the SPMP method produced in Visual C\# (Ikeya et al., 2011), helps to make measurements quickly, accurately, and easily just by marking points, producing results nearly 10 times faster than the manual method (Fig. 9). Particularly, it can measure 85 items including body axis and surface angles, lengths, heights, widths and depths by marking only 36 points on the profile of body silhouette of elderly women.

\subsection{Verification of SPMP by Comparing values}

3.2.1. Comparison of the value between SPMP and manual method

To verify the different results of measurements by SPMP and the conventional manual method (using a ruler and protractor), results of each method for thirteen elderly women were examined with a paired t-test. The paired t-test did not indicate any significant difference between the two methods in any measurement items for elderly women. However, the using of the manual method to measure 85 items took more than one hour compared to 10 minutes with SPMP, confirming SPMP's effectiveness to make measurements quickly and easily.

3.2.2. Comparison of the value between SPMP and Actual measurements

To confirm the difference between SPMP and the actual mea- 
Table 5. Mean difference between SPMP and actual measurement

\begin{tabular}{cccccc}
\hline \multirow{2}{*}{$\begin{array}{c}\text { Vertical Item } \\
(\mathrm{cm})\end{array}$} & \multicolumn{2}{c}{ SMPM } & \multicolumn{2}{c}{ ACTUAL } & Difference \\
\cline { 2 - 5 } & Mean & S.D. & Mean & S.D. & \\
\hline H(8)CLP & 105.10 & 2.33 & 104.86 & 2.64 & 0.24 \\
H(9)凸 & 99.32 & 3.62 & 99.43 & 3.86 & -0.11 \\
H(11)FWP & 91.68 & 3.39 & 92.36 & 2.71 & -0.67 \\
H(15)FH凸 & 81.82 & 4.90 & 82.58 & 4.66 & -0.77 \\
H16BH凸 & 71.82 & 3.56 & 72.05 & 3.63 & -0.23 \\
\hline Horizontal & \multicolumn{2}{c}{ SMPM } & ACTUAL & \\
\cline { 2 - 5 } Item (cm) & Mean & S.D. & Mean & S.D. & \\
\hline D(1)CL & 24.61 & 3.23 & 24.63 & 2.90 & -0.2 \\
D(2)WL & 23.46 & 3.04 & 24.33 & 3.23 & -0.87 \\
D(5)MHL & 26.48 & 2.47 & 26.70 & 2.12 & -0.22 \\
D6)HL & 23.57 & 2.03 & 23.54 & 2.07 & 0.03
\end{tabular}

SPMP, Semi-automatic Profile Measuring Program. Actual, Actual size. Number of subjects $=7$.

surement results, this study compared the results of the measurements of some items in the profile of body silhouettes of 7 elderly women as outlined below in Table 5 .

ISO 20685 is a 3D scanning methodology for internationally compatible anthropometric databases. It states the maximum allowable error between extracted values and traditionally measured values. The maximum mean difference is $5 \mathrm{~mm}$ for body depth and $4 \mathrm{~mm}$ for body height.

The mean difference between results of SPMP and actual values exceeded ISO 20685 standards for waist line depth $(8.7 \mathrm{~mm})$, waist line height $(6.7 \mathrm{~mm})$, and abdominal extension line height $(7.7 \mathrm{~mm})$. Except for the abdominal area, other mean differences are smaller than the ISO 20685 allowance. It is assumed that different values are easy to obtain when measuring the abdominal area because of the influence of breathing.

\subsection{Comparison of the results of SPMP by different} users

In order to demonstrate that SPMP is an accurate and reliable measurement program for the profile of body silhouettes, seven students majoring in clothing and textiles were selected to test usage and efficiency of the program. The seven students measured the same elderly woman using SPMP within 20 minutes for all 85 items.

After the seven students used SPMP, most values of coefficient of variation from all items were less than $5 \%$, except 8 items as shown in Table 6. For the FDP (point of tangent line from front waist point to front upper body) area, there is no guide line for the surface angle. Therefore most students marked highly different contact points. It is assumed that each student imagined a different location for the contact point without a guide line. Also, the most
Table 6. The value of measuring each item through SMPM among 7 students number of subjects $=7$. $\mathrm{CV}$, coefficient of variation for each item

\begin{tabular}{|c|c|c|c|c|c|}
\hline Angle item $\left({ }^{\circ}\right)$ & Mean & S.D. & Max & Min & $\mathrm{CV}(\%)$ \\
\hline $\mathrm{U}(7) \angle \mathrm{FwFd}$ & -3.25 & 0.70 & -2.18 & -4.13 & 21.65 \\
\hline $\begin{array}{l}\text { Vertical Item } \\
\qquad(\mathrm{cm})\end{array}$ & Mean & S.D. & Max & Min & $\mathrm{CV}(\%)$ \\
\hline L(11)Fb凹Fh凸 & 6.39 & 0.55 & 7.24 & 5.82 & 8.55 \\
\hline L(14)В凹Вһ凸 & 14.65 & 0.77 & 16.01 & 13.66 & 5.24 \\
\hline $\begin{array}{l}\text { Horizontal } \\
\text { Item }(\mathrm{cm})\end{array}$ & Mean & S.D. & Max & Min & $\mathrm{CV}(\%)$ \\
\hline W(7)F凸Fw & -0.50 & 0.20 & -0.26 & -0.73 & 39.89 \\
\hline W8F凸Fbw & -1.93 & 0.22 & -1.58 & -2.18 & 11.37 \\
\hline W(9F凸Fb凹 & -1.91 & 0.22 & -1.67 & -2.23 & 11.65 \\
\hline W(10) В凸Bw & 2.38 & 0.14 & 2.57 & 2.23 & 5.70 \\
\hline W12В凸В凹 & 3.60 & 0.21 & 3.98 & 3.38 & 5.73 \\
\hline
\end{tabular}

protruding points (凸) of the body such as $\mathrm{F}$ 凸, $\mathrm{B}$ 凸 $\mathrm{P}, \mathrm{PH}$ 凸 $\mathrm{P}$ and BH 凸 $\mathrm{P}$ areas are drawn using vertical guide lines. However, the elderly woman's body has a shallow curve at each point. Therefore the most protruding points and guide line's contact areas could not be picked up sharply at the same place by each student. It shows that students marked points using their individual experience, knowledge, and sense.

\subsection{Understanding morphology of elderly women through SPMP measurement}

This study analyzed the Pearson product moment correlation of all 85 item measurement results to find influential measurement items in the profile of body silhouettes of the 13 elderly women.

Especially, (10) $\angle \mathrm{McSn} \mathrm{McSn}$ helps to understand elderly women's posture as outlined in Fig. 10. (10) $\angle \mathrm{McSn}$, the axis angle in upper body from chest to SNP, has a higher positive correlation with (1) $\angle \mathrm{MwSn}$, the axis angle at the chest and waist to neck area $\left(\mathrm{r}=0.879,{ }^{* *} \mathrm{p}<0.01\right)$, but a lower correlation with (12) $\angle \mathrm{MwMc}$, the axis angle from waist to chest $(r=-0.353)$. This means that the abdominal area has a lower influence over the chest area in axis angle. Therefore, the best way to measure the curvature of the back of elderly women is by using the measurement of the angle between the chest and the side neck point, which is not affected by the waist. Furthermore (10) $\angle \mathrm{McSn}$ has a higher negative correlation in the lower body axis angle with two items, including (15) $\angle \mathrm{MtMw}$, from thigh to waist $\left(\mathrm{r}=-0.876,{ }^{* *} \mathrm{p}<0.01\right)$ (Fig. 11), and (7) $\angle \mathrm{MaMw}$, from ankle to waist( $\left.\mathrm{r}=-0.680,{ }^{*} \mathrm{p}<0.05\right)$. This indicates that the upper body of elderly women is curved to the front and the lower body is also curved backwards. However, it is still necessary to confirm this result in future studies with more subjects. 


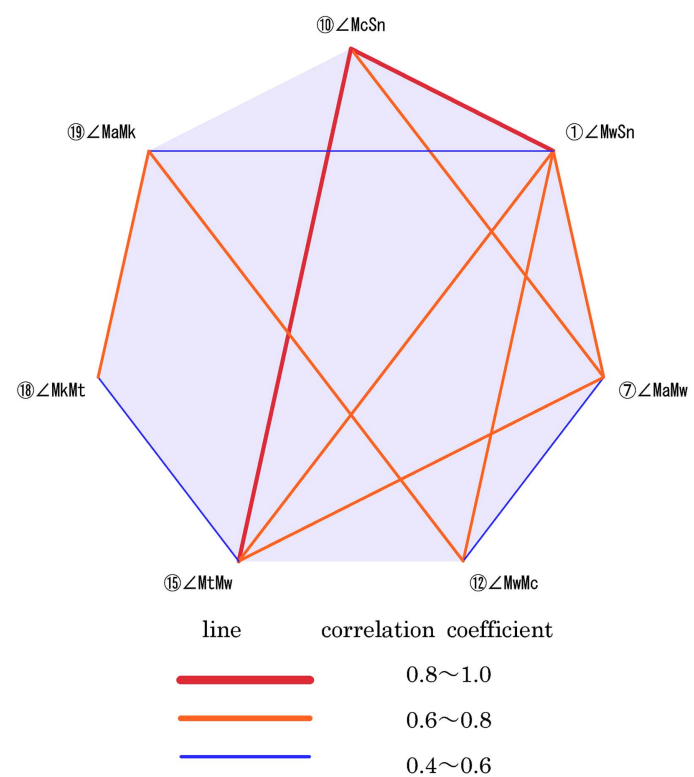

Fig. 10. Pearson product moment correlation coefficients among axis angle. Number of subjects $=13$.

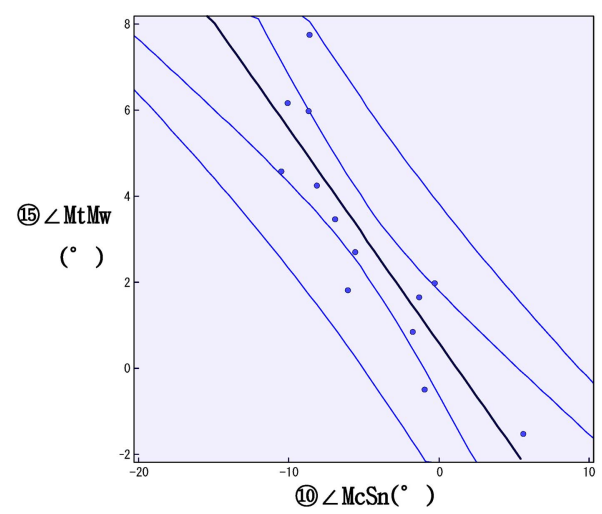

Fig. 11. Pearson product moment correlation between (10) $\angle \mathrm{McSn}$ and (15) $\angle \mathrm{MtMw}$.

Regression equation : $\mathrm{Y}=0.602197-0.495041 \mathrm{x}, \mathrm{r}=-0.876,{ }^{*} p<0.1(\mathrm{r}=$ Pearson product moment correlation coefficients, ${ }^{*}$ Significantly different $(p<.01)$ between (10) $\angle \mathrm{McSn}$ and (15) $\angle \mathrm{MtMw})$, confidence interval of the regression line : $95 \%$, Prediction inter of each data : $95 \%$

\section{Conclusion}

Until now, many studies about the profile of body silhouettes have used manual instruments such as a ruler and protractor. This approach involving repetitve measurement is inefficient and requires a great deal of time and effort. This study, however, by inventing a new device called the Semi-automatic Profile Measuring Program (SPMP), uses a digital method, which assists in measuring body shape for elderly women quickly and accurately.

By marking only 36 points on the photo of the profile of body silhouette, SPMP can automatically measure the angle of each of the body axes (19 items), surfaces (17 items), lengths (14 items), heights (16 items), widths (13 items), and depth (6 items). In total these 85 items are automatically measured very quickly, accurately, and easily after manually marking the initial 36 points.

We evaluated the suitability of SPMP for a total 85 items, comparing SPMP measuring results with manual methods (using a ruler and protractor) in thirteen elderly women with a paired t-test, and did not find a significant difference between them. When we compared the mean difference between SPMP and Actual measurement results in selected items from seven elderly women's measurements, besides the abdominal area which moves easily with breathing, we found smaller mean differences than those defined by ISO 20685. In order to investigate the effect of different individuals using SPMP, seven independent measurements of a single elderly woman were made by seven students using SPMP, and the values of coefficient of variation were less than $5 \%$ for all but 8 items. The results of this experiment show that in order to minimize differences in measurements between individuals, it is necessary to define the marking points of elderly women's bodies with greater objectivity and detail.

Finally, in order to understand the body posture of elderly women, we analyzed the correlation of all 85 items measurements, and found that the angle from the upper chest to the neck towards the front in the axis curved forward as much as the axis angle from the thigh to the waist $(r=-0.876, * * p<0.01)$ and the angle from the ankle to the waist $(r=-0.680, * p<0.05)$ bent backwards. This detailed analysis for elderly women's profile of body silhouette measurements will help to understand age-related changes in body posture in future studies.

\section{References}

Hirokawa, T. (2008). 3次元人体計測装置による3次元データ利用の高

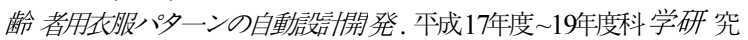
費補助金（基盤研究 (A) ) 研究成果報告書. [Automated design development of the clothes pattern for elderly people of the three-dimensional data use by the three-dimensional human body measuring device. Tokyo : 2005 2007 Scientific Research Subsidy (Based research (A)) Research Performance Report].

Igarashi, S., \& Makabe, H. (2001). The characteristics of body figure of middle and old aged women through body measurement data. Journal of Home Economics, 47, 61-70.

Iwasaki, K., Miyoshi, M., Hirokawa, T., Saito, K., \& Isozaki, A. (1998). Variation of body forms of middle and old aged women Part1 : Comparison of body forms of middle and old aged women according to discriminant analysis. The Japan Research Association for Textile End-Uses, 39(5), 57-65.

Ikeya, K., Matsuda, T., \& Kunimoto, A. (2011). Visual C\# 2010 逆引き大全555極 [555 secret of reverse Encyclopedia]. Tokyo: 
Shuwa System.

Japanese Industrial Standards. (2009). JIS Hand book. Tokyo: Author. Miyoshi, M., \& Nagatomi, A. (1993). A study on changes in the passage of time and classification of young women's side view somatotypes - Part 1-. Journal of Bunka Women 's University, 24, 93- 107.

Miyoshi, M. (2008). 服装造形学理論編 $I$ [Clothes making I]. Tokyo: Textbook press of Bunka Women's University.

Nakamoto, S., \& Miyoshi, M. (1980). A study on the side view classification of women's somatotypes - (1) A quatitative analysis of somatotype names - . Journal of Bunka Women's University, 11, 43-60.

Nam, Y. (1991). (A) Study on classification of somatotype based on the lateral view of women's upper body. Unpublished doctoral dissertation, Seoul National University, Seoul.

Nagatomi, A., \& Saito, K. (2003). Mechanism improvement and inspection of the somato type automatic movie camera. Journal of Bunka Women's University, 34, 15-22.

Oh, H. (2010). Changes in body shape in elderly women over 65. Unpublished master's dissertation, Bunka Women's University, Tokyo.

Okabe, K., \& Kurokawa, T. (2005a). Extraction of feature points from silhouette curves for body shape analysis in Japanese women. Japan Ergonomics Society, 4l(1) 11-16.
Okabe, K., \& Kurokawa, T. (2005b). Silhouette analysis and categorization of body shape changes in Japanese girls during periods of growth. Japan Ergonomics Society, 41(1), 17-23.

Shiraishi, S., \& Doi, D. (1982). Study of the characteristics of body form of old people. -Part 1 classification of side silhouette-. The Japan Research Association for Textile End-Uses, 23(2), 74-78.

Sugita, H., Tanaka, M., Takahashi, Y., Sato, Y., \& Yamada, H. (2001). Preference of female college students in judging the body silhouette of young women. Journal of Home Economics of Japan, 52(5) 31-37.

Takao, S. (1970). Harmony between design of women's dresses and physical types -Part 4- Forms around the trunk of the body and their classification. Journal of Home Economics of Japan, 21(5), 49-54.

Watanabe, K., Furumatsu, Y., \& Matsuyamay, Y. (1999). Analysis of the dorsal shape of elderly Japanese women and a comparison with young women. Journal of Home Economics of Japan, 50(12), 39-48.

Yanagisawa, S., Suzuki, H., Ito, R., \& Shimizu, K. (1968). A study on the body silhouette of the Japanese females. Journal of Home Economics of Japan, 19(2), 46-49.

(Received 28 May 2012; 1st Revised 26 September 2012; Accepted 22 October 2012)

Copyright $($ C The Korean Society for Clothing Industry. 2012. This is an open access article distributed under the terms and conditions of the Creative Commons Attribution Non-Commercial license (http://creativecommons.org/licenses/by-nc/3.0/), which permits unrestricted non-commercial use, distribution, and reproduction in any medium, provided the original work is properly cited. 